\title{
Drug repurposing strategies in the discovery of antifungal agents
}

Qian Zhanga ${ }^{\mathrm{a}}$, Fangyan Liu ${ }^{\mathrm{a}}$, Meng Zeng ${ }^{\mathrm{a}}$, Caiyan Xin ${ }^{\mathrm{a}}$, Jinping Zhanga ${ }^{\mathrm{a}}$, Yingyu Mao ${ }^{\mathrm{a}^{*}}$, Zhangyong

$$
\text { Song, } \mathrm{a}^{\mathrm{a}, \mathrm{c}} \mathrm{c}^{*}
$$

a School of Basic Medical Sciences, Southwest Medical University, Luzhou 646000, People's Republic of China.

b Molecular Biotechnology Platform, Public Center of Experimental Technology, Southwest Medical University, Luzhou 646000, People's Republic of China.

c Laboratory of Molecular Pharmacology, Department of Pharmacology, School of Pharmacy, Southwest Medical University, Luzhou 646000, People's Republic of China.

* These authors are co-correspondence authors.

Author 1: Given name: Qian_Family name: Zhang_Email: Zq1729174802@163.com

Author 2: Given name: FangyanＦamily name: Liu_Email: liufangyan1989@163.com

Author 3: Given name: Meng Family name: Zeng Email: zengmeng19881026@163.com

Author 4: Given name: Caiyan Family name: Xin_ Email: xincy0211@126.com

Author 5: Given name: Jinping Family name: Zhang Email: zhangjpwcx@163.com

Author 6: Given name: Yingyu Family name: Mao_ Email: tianya1000@126.com

Author 7: Given name: Zhangyong Family name: Song Email: szy83529@163.com; institutional email: SongZY@swmu.edu.cn

Tel/Fax: +86-0830-3161506

\begin{abstract}
The morbidity and mortality caused by invasive fungal infections is increasing across the globe due to developments in transplant surgery, the use of immunosuppressive agents, and the emergence of drug-resistant fungal strains, which has led to a challenge in terms of treatment due to the limitations of three classes of drugs. Hence, it is imperative to establish effective strategies to identify and design new antifungal drugs. Drug repurposing is an effective way of expanding the application of existing drugs. In the last years, various existing drugs have been shown to be useful in the prevention and treatment of the invasive fungi. In this review, we summarize the currently used antifungal agents. In addition, the most up to date information on the effectiveness of existing drugs with antifungal activity is discussed. Moreover, the antifungal mechanisms of existing drugs are highlighted. These data will provide valuable knowledge to stimulate further investigation and clinical application in this field.
\end{abstract}

Keywords: drug repurposing; antifungal therapy; antifungal mechanism; clinical application; antifungal agent 


\section{Introduction}

Fungal infection has become a significant event leading to over 1.5 million deaths annually worldwide [1]. To date, the most common fungal infections related to human mortality and morbidity are caused by Cryptococcus, Candida, and Aspergillus [2]. The impact of mycoses has increased due to developments in transplant surgery, chemoradiotherapy, hemodialysis, and the use of immunosuppressive agents, especially in patients with immunodeficiency disorders, with an estimated mortality ranging from $35 \%$ to $45 \%$ [3]. Hence, antifungal therapy represents a challenging problem for clinicians. In addition, the limited number of antifungal agents in the clinic can induce side-effects and a great number of drug-resistant or multidrug resistant strains have emerged. Candida auris, a multidrug resistant fungus, has shown a global increase in recent years. Importantly, some of these infections are resistant to almost all current antifungal agents [4]. In New Delhi, it was reported that 15 COVID-19 patients had secondary candidiasis in the intensive care unit (ICU), two-thirds of which were caused by $C$. auris, and the mortality rate was up to $60 \%$ [5].

Currently, the first-line antifungal agents for invasive fungal infections are voriconazole, itraconazole, amphotericin B, and echinocandins [6]. However, due to the existence of toxicity and drug-resistant strains, the present antifungal options have become more restricted. A variety of approaches have been employed to conduct antifungal therapies, such as the synthesis of new substances, the use of extracts from organisms, the development of old drugs to change the use or form of fungal disease, and an association between known antifungal drugs and non-antifungal agents [7]. Drug repurposing is an established strategy for the treatment of invasive fungal infections due to the excellent antifungal activity of these drugs. Several agents have recently been confirmed to serve as antifungal candidates in the treatment of mycoses. The purpose of this review is to present a series of known drugs that have been investigated for their application in the treatment of fungal infections. Firstly, the strategies, mechanisms, and challenges of current antifungal drugs are described. Secondly, the extensive application and antifungal mechanisms of drugs with antifungal activity that had been used in the clinic to treat non-mycotic infections are highlighted.

\section{Current antifungal drugs used in the clinic}

Since the first active antimycotic griseofulvin was recognized in 1939, a multitude of antifungal agents have been used clinically. The three main types currently used in the clinic are polyenes, azoles, and echinocandins. In fungi, ergosterol, located in the cell membrane, regulates membrane structure permeability, mobility, and substance transportation by making direct linkages with the phospholipid membrane [8]. The representative polyene drug is amphotericin $\mathrm{B}$, which can bind to ergosterol from lipid bilayers and form large and extramembranous aggregates [8]. These extramembranous aggregates lead to the formation of transmembraneal pores, which can leak cellular components. This results in the death of pathogenic fungi [8]. As the "gold standard" for combating invasive fungal infections for decades, amphotericin $\mathrm{B}$ has a broad spectrum of antifungal activity against yeasts and molds [9]. For instance, an investigation of 78 Candida spp. clinical strains, showed that all examined free-living cells, were susceptible to amphotericin B [10]. When amphotericin B was combined with caspofungin and voriconazole in Aspergillus species, the 
fractional inhibitory concentration (FIC) index was only 0.10-0.22 [11]. However, it has limited clinical applications due to toxicity, which includes nephrotoxicity and infusion-related reactions such as chest pain, dyspnea, hypoxia, flushing, and urticaria [12]. To resolve this problem, lipid formations of amphotericin B, including liposomal amphotericin B (LAmB), AmpB lipid complex (ABLC), and AmpB colloid dispersion (ABCD) were developed [9]. Toxicity was greatly reduced using these formulations; however, the results were disappointing due to their low permeability at therapeutic concentration [13].

Due to the safety and wide availability, the azoles (including fluconazole, itraconazole, voriconazole, posaconazole, and isavuconazole) are the most widely used antifungal agents, and can be used against the majority of fungi as they inhibit the cytochrome P450-dependent enzyme $14 \alpha$ demethylase (Cyp51) [14]. Lanosterol generating into ergosterol was blocked when azole inhibited the Cyp51.The sterol intermediates can also promote accumulated toxicity [15]. The azoles have typical fungicidal effects on molds and are fungistatic in yeasts [16]. For example, voriconazole is an effective frontline therapy for invasive aspergillosis, and the curative rate was $52.8 \%$ in a randomized trial [17]. However, the extensive use of azoles has subsequently led to the emergence of acquired azole resistance, particularly in Aspergillus species [18]. A resistance rate of $26 \%$ was found in A. fumigatus culture-positive patients in the ICU [19]. Azoles can also bind to the human cytochrome P450 enzyme system (CYP450), leading to reduced antifungal efficiency [20].

Echinocandins are a group of effective antifungal agents which are, according to current international guidelines, useful for the primary treatment of invasive candidiasis [21]. Anidulafungin, caspofungin, and micafungin are representatives of this group [22]. Compared with amphotericin B and fluconazole, echinocandins rarely cause resistance, have a good safety profile, better clinical outcomes and have been used for two decades. The mechanism of echinocandins mainly involves inhibition of cell wall synthesis by inhibiting $\beta$-1,3-D-glucan synthase, a key cell wall component of pathogenic fungi. Following treatment with echinocandins, the buried glucan cell wall architecture can be exposed, which induces abnormal morphology and growth limitation. The therapeutic concentration of $2 \mu \mathrm{g} / \mathrm{mL}$ caspofungin significantly decreased the metabolism of $C$. albicans and C. parapsilosis yeasts without or with the biofilm [23]. The time-kill methodology of C. albicans biofilms, treated with caspofungin, displayed at least $99 \%$ killing at physiological concentrations. Investigations in AIDS patients, who were unable to tolerate amphotericin B, have also shown that caspofungin is an efficient therapeutic option for azole-resistant Candida infections $[24,25]$. Anidulafungin is an excellent therapeutic choice against Aspergillus and Candida species, including those resistant to either fluconazole or amphotericin B. A literature review mentioned that it was a superior option in the treatment of oesophageal candidiasis and candidemia compare with fluconazole [26]. Micafungin also exhibits excellent activity on Candida spp. resistant to multiple azoles, and $8 \mu \mathrm{g} / \mathrm{mL}$ of micafungin demonstrated a $57 \%$ antifungal rate in C. parapsilosis [27]. Nevertheless, probably due to the differences in cell wall composition or structure, this class is largely inactive in most filamentous fungi including Zygomycetes and Fusarium species [28]. In addition, C. neoformans is naturally resistant to echinocandins, which are completely ineffective in 
treating cryptococcosis [29]. Additionally, due to their characteristic large molecular weight, low oral bioavailability, and limited absorption in the gastrointestinal tract, these drugs are only administered intravenously.

Azole resistance among Candida species such as C. auris and Aspergillus species, as well as echinocandin resistance in C. glabrata is an alarming problem [18]. In addition, other molds such as Scedosporium and Fusarium species have reduced susceptibility to clinically available antifungal drugs [18]. Although amphotericin B is recognized to have excellent antifungal activity, there are still fungi, such as Candida lusitaniae and Aspergillus terreus that show intrinsic resistance to amphotericin B [30]. Consequently, the development of new antifungals is needed to resolve this issue.

\section{Drug repurposing strategy}

With the changes in infection disease spectra and a clearer mechanism of disease, the strategy of drug repurposing to tap into new applications of existing drugs, requires innovative clinical in-depth investigation of pharmacological mechanisms. A large number of drugs with new indications have emerged. For example, aspirin, a traditional drug with analgesic and antipyretic activity initially, and is now gradually being used in the prevention and treatment of multi-system disease that involves cardiovascular disease, stroke, and digestive tract cancers [31-34]. Vitamin D is widely used to regulate calcium and phosphate metabolism for bone health [35]. Recent studies have found that vitamin D deficiency is associated with an increased risk of cardiovascular disease, diabetes, hypercholesterolemia, and even the COVID-19 [36,37]. Metformin, originally used to treat diabetes, has so far more than a dozen potential new functions including the treatment and prevention of cancer, cardiovascular disease, and mental illness such as infantile autism and cognitive disorder [38-44].In addition, drug repurposing is also very significant in the development of new antifungal drugs, the effectiveness of existing drugs with antifungal activity have been associated with exciting non-antifungal agents chiefly consisting of antibacterial drugs, immunosuppressants, statins, antiarrhythmic drugs, antipsychotic drugs, antidepressant drugs, and non-steroidal antiinflammatory drugs (NSAIDs).

\subsection{Antibacterial drugs}

The discovery of antibacterial drugs has been the greatest invention of medical science in reducing morbidity and mortality, and these drugs are mainly composed of tetracyclines (e.g., minocycline and doxycycline), aminoglycosides (e.g., gentamicin, neomycin, paromomycin, ribostamycin, and streptomycin), and quinolone polypeptides (e.g., moxifloxacin and gatifloxacin). Traditionally, antibacterial drugs were commonly used as medical treatments for infectious diseases caused by gram-negative bacteria, gram-positive bacteria, mycoplasma, chlamydia, rickettsia, as well as spirochaetes. A number of reports have revealed that antibacterial drugs also have broad-spectrum antifungal activity (Table 1). In general, they are commonly used alone or in combination to regulate the gene expression levels of adhesion, hypha, or biofilm formation, to decrease extracellular glycan level and cell surface hydrophobicity, and even to inhibit efflux pump activity. In Fusarium spp., tobramycin alone has $80 \%$ activity and a $76 \%$ synergistic effect with amphotericin B or 
voriconazole, respectively, and increases the permeability of the cell wall and cell membrane of fungi when combined with antifungal agents [45]. Similar findings have also been confirmed for polymyxin $\mathrm{B}$ which mainly combines with ketoconazole, micafungin, and amphotericin $\mathrm{B}$ in $C$. albicans to alter the permeability of the cell membrane [46]. Moreover, polymyxin B can integrate anionic lipids on the fungal membrane both alone and combined with fluconazole with a minimum concentration $8 \mu \mathrm{g} / \mathrm{mL}$ for Fusarium spp., C. neoformans, Rhizopus oryzae, and A. fumigatus, which destroys the membrane integrity [45,47].

Biofilms represent one of the major virulence factors in pathogenic fungi, which develop on the surfaces of stents, shunts, prostheses, implants, endotracheal tubes, pacemakers, and various types of catheters [48]. Compared to planktonic cells, the interior biofilm cells display severe resistance to a wide variety of clinical antifungal agents. A small subset of yeast cells in C. albicans biofilms, were found to be highly resistant to amphotericin B. This resistance was independent of the upregulation of efflux pumps and cell membrane composition [48]. When combined with clarithromycin, the permeability barrier of the biofilm matrix was altered, which resulted in increased penetration of amphotericin B [49]. In addition, doxycycline, tigecycline, and rifampicin were also found to enhance the activity of amphotericin B to suppress biofilm formation [45, 4954].

Thus, antibacterial drugs have potential antifungal value due to their good antifungal activity. However, human health is based on the balance of microbiota [55,56]. Although antibacterial drugs have been approved for the treatment of invasive fungal infections, many problems still need to be considered. For instance, antibiotic treatment will reduce the composition of colonized microbiota [57]. Moreover, many antimicrobial drugs can promote fungal growth and enhance fungal pathogenicity indirectly by disrupting the microbiome and eliminating anaerobic bacteria, which might inhibit fungi, especially in the gut [57]. Our previous investigation (unpublished article) also showed that the antifungal applications of antibiotics interfere with the homeostasis of symbiotic bacteria and fungi in the body. Moreover, dysbiosis of microbiota is responsible for the occurrence of many other diseases in humans such as cardiovascular, cancer, allergy, and the microbiota also affect the human immune system and the synthesis of nutrients [58,59]. In addition, the pharmacokinetics of antibiotics with antifungal activity in vivo also require further investigation.

\subsection{Immunosuppressants}

Immunosuppressants are another example of drug repurposing due to their antifungal activity. It is known that immunosuppressants mainly include calcineurin inhibitors (e.g., cyclosporine; tacrolimus, FK506; and pimecrolimus), target of rapamycin inhibitors (e.g., rapamycin), antimetabolic agents (e.g., mycophenolic acid, MPA; mizoribine, MZP), and glucocorticoids (e.g., hydrocortisone, budesonide, and dexamethasone). Initially, rapamycin was found to be an antifungal agent and inhibited yeasts including C. albicans, dermatophytes, Microsporum gypseum, and Trichophyton granulosum [75]. Rapamycin, probably acting on the recombinant FK506 binding protein (FKBP) complex, showed activity on clinical isolates of Candida compared with candicidin, nystatin, and amphotericin B in an in vitro investigation [76]. The immunosuppressants found to 
have antifungal ability are briefly summarized in Table 2 .

Inosine monophosphate dehydrogenase (IMPDH), is a crucial enzyme in de novo guanine nucleotide biosynthesis, and plays an important role in the rapid proliferation of cells [77]. A recent investigation found that benzo[b]thiophene 1,1-dioxide, an IMPDH inhibitor, can weaken the virulence of C. neoformans or kill it entirely [78]. In addition, MPA and MZP, other types of IMPDH inhibitors, were confirmed to have significant antifungal effects in C. albicans and C. neoformans by disrupting de novo GTP biosynthesis [79-81]. Ribavirin, an antiviral agent, is also a type of IMPDA inhibitor. Interestingly, it was found that ribavirin displayed potent antifungal activity in $C$. albicans in monotherapy or in combination with fluconazole, itraconazole, and posaconazole in vitro and in vivo. The antifungal mechanism involves disruption of vacuolar function and the reduction of extracellular phospholipase activity $[82,83]$.

Calcineurin, a conserved serine-threonine specific phosphatase, consists of a catalytic subunit and a regulatory subunit $[84,85]$. It is one of the important mediators in calcium signals and is involved in hyphal/mycelium formation in C. neoformans and A. fumigatus [86]. Clinical experience has suggested that calcineurin inhibitors (cyclosporin A and FK506) can decrease the mortality of invasive Aspergillosis by forming protein-drug complexes [87,88]. Glucocorticoids, such as hydrocortisone, budesonide, and dexamethasone, are immunosuppressants with antifungal activity [89-91]. However, the antifungal activity of glucocorticoids remains controversial. For instance, an investigation found that hydrocortisone enhanced the growth of Aspergillus spp. [92]. Betamethasone, one of the glucocorticoids, is also capable of promoting hyphal formation, stimulating extracellular phospholipase production, and decreasing the anti-C. albicans activity of amphotericin B and nystatin [93]. Moreover, an in vivo investigation also found that glucocorticoids increased fungal burden in the gastrointestinal tract in rats [94], and enhanced the frequency of fungal translocation in mice [95]. Thus, the practical application of glucocorticoids in fungal infections requires further investigation.

Immunosuppressant-treated fungal cells show phenotypes consistent with inhibition of planktonic cell growth, morphological transformation, and biofilm formation [96, 97]. However, at present, the exact mechanisms of immunosuppressant synergism with various antifungal drugs have not been delineated. In particular, the TOR as a representative target may be a promising antifungal approach. To date, there are no relevant fungal-specific inhibitors available [98]. On the other hand, the use of immunosuppressants can inhibit the host immune response, which increases the risk of fungal infection. According to a large number of in vitro antifungal experiments, immunosuppressants do have potent antifungal effects. However, there are no clinical studies to demonstrate whether immunosuppressants have antifungal effects in humans.

\subsection{Statins}

Statins are firstly known as lipid-lowering and cholesterol-lowering drugs as they inhibit HMGCoA reductase (an essential enzyme in cholesterol biosynthesis) [114], and are classified according to their hydrophobicity into hydrophilic statins (pravastatin and rosuvastatin) and lipophilic statins (atorvastatin, cerivastatin, fluvastatin, lovastatin, pitavastatin, and simvastatin). It has been 
confirmed that statins exert a broad spectrum of anti-fungal effects on Candida spp., Aspergillus spp., and Zygomycetes [115]. Table 3 shows a brief summary of the statins with antifungal ability. The antifungal mechanism of statins is focused primarily on the biofilm. For example, the changes in the main components of the biofilm or genes associated with fungal biofilm formation following monotherapy or/and synergism of antifungal agents have been verified. Inexplicably, antifungal activity findings are inconsistent. For instance, pravastatin has synergistic effects with fluconazole by inhibiting farnesol production against C. albicans [116], and in contrast, no synergy was found between pravastatin and fluconazole in vitro in another investigation [117]. In addition, a study even reported that pravastatin did not inhibit the growth of Candida spp. [118]. The reason for this may be due to differences in fungi strains, and different methodology. These contradictory findings require clarification in further investigations.

\subsection{Antiarrhythmic drugs}

Antiarrhythmic drugs, which are used in the prevention and treatment of tachycardia, bradycardia, or arrhythmia, include sodium channel antagonists, $\beta$-receptor blockers, potassium channel blockers (PCRs), and calcium channel blockers (CCBs). Trails have shown that amiodarone, PCRs, and CCBs exhibit favorable antifungal activity when administered alone or combined with conventional antifungals. CCBs, as the name suggests, prevent calcium ions entering cells and maintain metabolic processes. Verapamil (verapamil hydrochloride), a phenylalkylamine CCB, mainly combats $C$. albicans by affecting hyphal development, adhesion, gastrointestinal colonization or increasing strain susceptibility to oxidative stress [131,132]. In addition, verapamil enhances the antifungal activity of tunicamycin or fluconazole against $C$. albicans during biofilm formation and pre-formed biofilms [133]. In A. fumigatus, the drug efflux pump was blocked and ergosterol content was decreased following treatment with verapamil and itraconazole simultaneously [134]. Other CCBs, such as diltiazem, nicardipine, and nifedipine, have shown antifungal activity against C. albicans, C. glabrata, Ascomycetous and Mucoralean fungi, either alone or in combination with antifungals [135-137]. Amiodarone is known to block potassium, sodium and calcium channels, and is commonly used to treat and prevent tachyarrhythmia [138140]. In pathogens, amiodarone mainly disrupted calcium homeostasis to elicit high levels of cytoplasmic calcium, leading to cell death in Cryptococcus spp., Aspergillus spp., Fusarium oxysporum, C. albicans, C. tropicalis, and Saccharomyces cerevisiae [141-147]. In addition, amiodarone displayed potent fungicidal effects at low dose combined with fluconazole and miconazole [148]. Hence, calcium channels may be potential targets in the therapy of fungal-related infections.

\subsection{Antipsychotic drugs}

Antipsychotic drugs include benzamides, butyrophenones, dibenzoxazepine, phenothiazines, and thioxanthene. Phenothiazines are the first generation of antipsychotics, and are mainly used to treat schizophrenia and mania. In addition, phenothiazines possess multiple effects such as altering the metabolism of cyclic nucleotides, modifying the structure of membranes, binding to calmodulin and they participate in many intracellular responses [149], which may explain the antifungal action of 
phenothiazines $[150,151]$. Chlorpromazine and trifluoperazine are representative phenothiazines. Both block the central dopamine $\mathrm{D}_{2}$ receptor to improve symptoms in mentally ill patients. They have excellent activity against Candida spp., C. neoformans either alone or in combination with ketoconazole and amphotericin B [150-154]. Trifluoperazine also has fungicidal effects on $C$. neoformans, especially on melanized cells [155]. In addition, chlorpromazine and trifluoperazine have fungicidal effects on Zygomycetes when concentrations reach 25-200 $\mu \mathrm{g} / \mathrm{mL}$. Moreover, it has synergistic effects with amphotericin B [156]. The minimum fungicidal concentration of chlorpromazine and trifluoperazine in Aspergillus spp., Scedosporium, and Pseudallescheria ranged between 10 and $64 \mu \mathrm{g} / \mathrm{mL}[157,158]$. Flunarizine is a difluorinated derivative of piperazine as well as a potent CCB. It has the same structure as phenothiazines. Flunarizine also exhibits broadspectrum antifungal effects against Candida spp., Cryptococcus spp. and Zygosaccharomyces spp. alone or jointly with ketoconazole in vitro probably by inhibiting calmodulin activity and increasing the penetration of ketoconazole through cell walls [159].

Compared to the traditional antifungal drugs, the main advantage of phenothiazines is that they can cross the blood-brain barrier and improve bioavailability. Moreover, the levels achievable in the brain with antipsychotic therapeutic doses range from 50 to $100 \mu \mathrm{g} / \mathrm{mL}$; however, the range in plasma is only between 0.5 and $1 \mu \mathrm{g} / \mathrm{mL}$ [158].

\subsection{Antidepressant drugs}

There are currently many types of antidepressant drugs used in the clinic. These mainly include monoamine oxidase inhibitors (e.g., phenelzine), tricyclic (e.g., amitriptyline and doxepin), tetracyclic (e.g., maprotiline), and selective serotonin reuptake inhibitors (SSRIs) (e.g., fluoxetine and paroxetine). Of these, SSRIs are first-line antidepressant drugs with low side-effects. They not only have anti-depression activity, but also have anti-anxiety activity [160]. SSRIs effectively inhibit the uptake of serotonin by neurons from synaptic spaces, which increase the availability of this neurotransmitter in these spaces and improves the emotional states, and treats depressive mental disorders [161]. Encouragingly, SSRIs have been shown to have positive antifungal activity in various studies. An antifungal experiment showed that fluoxetine could kill some azole-resistant Candida spp. strains in vitro with or without fluconazole. Moreover, they also improved the survival rate of Galleria mellonella in vivo. The antifungal mechanism involves inhibition of extracellular phospholipase activity by down-regulated SAP1-4 genes in resistant $C$. albicans $[162,163]$. The $S A P$ genes encode secreted aspartyl proteinases $(S A P)$, which are key virulence factors and play an important role in the growth, development, and pathogenicity of Candida spp. [164]. In addition, fluoxetine exhibited synergistic effects against $C$. albicans biofilms and relieved oral candidiasis in infected mice when combined with caspofungin [165]. Sertraline, another type of SSRI, also showed positive antifungal activity alone or in combination with antifungal agents. It can reduce the fungal burden, improve survival rate and impair tissue damage in mice and G. mellonella $[166,167]$. Similar results showed that sertraline had fungistatic or fungicidal effects in Candida spp., Coccidioides immitis, C. neoformans, Trichosporon asahii, and A. fumigatus [166-171]. 
274 NSAIDs, act mainly by inhibiting the activity of cyclooxygenase to reduce the production of prostaglandins (PGs), thus have antipyretic, analgesic, anti-inflammatory, and other functions [172].

276 NSAIDs, especially aspirin, etodolac, diclofenac, celecoxib, nimesulide, ibuprofen, meloxicam,

277 ketoprofen, tenoxicam, and ketorolac exhibited favorable anti-C. albicans effects by inhibiting the synthesis of fungal PGs, which play an important role in biofilm development, adhesion, and morphogenesis in C. albicans [173,174]. In addition, most of these drugs had synergistic or additive (ketorolac) activity with fluconazole against C. albicans [174]. Subsequently, the antifungal mechanisms of aspirin and ibuprofen have become clearer. They can, by activating the highosmolarity glycerol pathway, induce the accumulation of reactive oxygen species (ROS), and then simultaneously damage the integrity of cell membranes leading to the death of Cryptococcus cells [175]. In addition, aspirin and ibuprofen combined with fluconazole, caspofungin, and amphotericin B have effects on fungi $[175,176]$. Ibuprofen also has anti-Sporothrix activity singly (median MIC of $256 \mu \mathrm{g} / \mathrm{mL}$ ) or in combination with antifungal agents including amphotericin B, itraconazole, and terbinafine [177]. Diclofenac sodium can down-regulate the expression of $E f-1$ gene, which is involved in cellular RNA transport, cell cycle, and apoptosis [178], thus resulting in a reduction in the formation of A. fumigatus filaments [179].

\section{Conclusion}

In this review, we summarized the antifungal effects of a number of non-antifungal agents. In addition, some antitumor agents such as miltefosine [180], tamoxifen [181], methotrexate, [182] and antiepileptic drugs [183] have also been reported to have antifungal effects. The use of drug repurposing strategies in the discovery of novel antifungal agents is a revelation in the identification of new antifungal drugs through structural readjustment. With regard to their related antifungal targets, there are still many antifungal mechanisms of the above-mentioned drugs which are unclear (Fig. 1). To reveal the precise targets, further investigations should be performed using transcriptome analysis and molecular techniques, which will lay the foundation for the development of novel antifungal drugs for example using target design. In addition, these antifungal experiments have only focused on either in vitro studies or animal model experiments. There is not enough clinical evidence to prove their practical use in the clinic. Moreover, many factors, such as changes in medium composition will perhaps lead to different or completely opposite results. In vivo studies, differences between animal models or homogeneous animal models and differences in pharmacokinetic and pharmacodynamic parameters of compounds in these models, and the effects of host-derived serum and, cellular factors should be clarified. Hence, it is essential to use systematic and standard research approaches, as well as collect more clinical data to evaluate the antifungal effectiveness of these agents.

This research was supported financially by Sichuan Province Administration of Traditional Chinese Medicine (2020JC0129), Technology strategic cooperation project of Luzhou municipal people's government-Southwest Medical University (2020LZXNYDJ38, 2020LZXNYDJ23), and 
313 2020ZRQNB066). 


\section{Reference}

1. Deaguero IG.; Huda MN.; Rodriguez V.; Zicari J.; Al-Hilal TA.; Badruddoza AZM.; Nurunnabi M. Nano-vesicle based anti-fungal formulation shows higher stability, skin diffusion, biosafety and anti-fungal efficacy in vitro. Pharmaceutics. 2020, 12, 516.

2. Boral H.; Metin B.; Döğen A.; Seyedmousavi S.; Ilkit M. Overview of selected virulence attributes in Aspergillus fumigatus, Candida albicans, Cryptococcus neoformans, Trichophyton rubrum, and Exophiala dermatitidis. Fungal Genet Biol. 2018, 111, 92-107.

3. Drgona L.; Khachatryan A.; Stephens J.; Charbonneau C.; Kantecki M.; Haider S.; Barnes R. Clinical and economic burden of invasive fungal diseases in Europe: focus on pre-emptive and empirical treatment of Aspergillus and Candida species. Eur J Clin Microbiol Infect Dis. 2014, 33, $7-21$.

4. Du H.; Bing J.; Hu T.; Ennis CL.; Nobile CJ.; Huang G. Candida auris: epidemiology, biology, antifungal resistance, and virulence. PLoS Pathog. 2020, 16, e1008921.

5. Chowdhary A.; Tarai B.; Singh A.; Sharma A. Multidrug-resistant Candida auris infections in critically ill coronavirus disease patients, India, April-July 2020. Emerg Infect Dis. 2020, 26, 26942696.

6. Zhao Y J.; Khoo A L.; Tan G.; Teng M.; Tee C.; Tan B H.; Ong B.; Lim B P.; Chai L Y A. Network meta-analysis and pharmacoeconomic evaluation of fluconazole, itraconazole, posaconazole, and voriconazole in invasive fungal infection prophylaxis. Antimicrobial Agents and Chemotherapy. 2016, 60, 376-386.

7. Robbins N.; Wright GD.; Cowen LE. Antifungal drugs: the current armamentarium and development of new agents. Microbiol Spectr. 2016, 4, 5.

8. Anderson TM.; Clay MC.; Cioffi AG.; Diaz KA.; Hisao GS.; Tuttle MD.; Nieuwkoop AJ.; Comellas G.; Maryum N.; Wang S.; Uno BE.; Wildeman EL.; Gonen T.; Rienstra CM.; Burke MD. Amphotericin forms an extramembranous and fungicidal sterol sponge. Nat Chem Biol. 2014, 10, 400-6.

9. Ostrosky-Zeichner L.; Marr K A.; Rex J H.; Cohen S H. Amphotericin B: time for a new "gold standard". Clin Infect Dis. 2003, 37, 415-425.

10. Prazynska M.; Gospodarek E. In vitro effect of amphotericin B on Candida albicans, Candida glabrata and Candida parapsilosis biofilm formation. Mycopathologia. 2014, 177, 19-27.

11. O'shaughnessy E M.; Meletiadis J.; Stergiopoulou T.; Demchok J P.; Walsh T J. Antifungal interactions within the triple combination of amphotericin $\mathrm{B}$, caspofungin and voriconazole against Aspergillus species. J Antimicrob Chemother. 2006, 58, 1168-1176.

12. Roden M M.; Nelson L D.; Knudsen T A.; Jarosinski P F.; Starling J M.; Shiflett S E.; Calis K.; Dechristoforo R.; Donowitz G R.; Buell D.; Walsh T J. Triad of acute infusion-related reactions associated with liposomal amphotericin B: analysis of clinical and epidemiological characteristics. Clin Infect Dis. 2003, 36, 1213-1220.

13. Smitherman L. In brief: antifungal drugs. Pediatrics in Review. 2016, 37, 267-268. 
14. Emami S.; Tavangar P.; Keighobadi M. An overview of azoles targeting sterol $14 \alpha-$ demethylase for antileishmanial therapy. Eur J Med Chem. 2017, 135, 241-259.

15. Onyewu C.; Blankenship JR.; Del Poeta M.; Heitman J. Ergosterol biosynthesis inhibitors become fungicidal when combined with calcineurin inhibitors against Candida albicans, Candida glabrata, and Candida krusei. Antimicrob Agents Chemother. 2003, 47, 956-64.

16. Perlin DS.; Rautemaa-Richardson R.; Alastruey-Izquierdo A. The global problem of antifungal resistance: prevalence, mechanisms, and management. Lancet Infect Dis. 2017, 17, e383e392.

17. Haidar G.; Singh N. How we approach combination antifungal therapy for invasive aspergillosis and mucormycosis in transplant recipients. Transplantation. 2018, 102, 1815-1823.

18. Wiederhold NP. Antifungal resistance: current trends and future strategies to combat. Infect Drug Resist. 2017, 10, 249-259.

19. van Paassen J.; Russcher A.; In 't Veld-van Wingerden AW.; Verweij PE.; Kuijper EJ. Emerging aspergillosis by azole-resistant Aspergillus fumigatus at an intensive care unit in the Netherlands, 2010 to 2013. Euro Surveill. 2016, 21, 10.2807/1560-7917.ES.2016.21.30.30300.

20. Wiederhold NP. The antifungal arsenal: alternative drugs and future targets. Int J Antimicrob Agents. 2018, 51, 333-339.

21. Chang C C.; Slavin M A.; Chen S C A. New developments and directions in the clinical application of the echinocandins. Arch Toxicol. 2017, 91, 1613-1621.

22. Emri T.; Majoros L.; Tóth V.; Pócsi I. Echinocandins: production and applications. Appl Microbiol Biotechnol. 2013, 97, 3267-3284.

23. Cocuaud C.; Rodier M H.; Daniault G.; Imbert C. Anti-metabolic activity of caspofungin against Candida albicans and Candida parapsilosis biofilms. J Antimicrob Chemother. 2005, 56, 507-512.

24. Ramage G.; Vandewalle K.; Bachmann S P.; Wickes B L.; Lopez-Ribot J L. In vitro pharmacodynamic properties of three antifungal agents against preformed Candida albicans biofilms determined by time-kill studies. Antimicrob Agents Chemother. 2002, 46, 3634-3636.

25. Garbino J. Caspofungin--a new therapeutic option for oropharyngeal candidiasis. Clin Microbiol Infect. 2004, 10, 187-189.

26. Vazquez J A. Anidulafungin: a new echinocandin with a novel profile. Clin Ther. 2005, 27, 657-673.

27. Gil-Alonso S.; Jauregizar N.; Eraso E.; Quindós G. Postantifungal effect of micafungin against the species complexes of Candida albicans and Candida parapsilosis. PloS one. 2015, 10, e0132730-e0132730.

28. Perlin DS. Cell wall-modifying antifungal drugs. Curr Top Microbiol Immunol. 2020, 425, 255-275.

29. Denning DW. Echinocandin antifungal drugs. Lancet. 2003. 362, 1142-1151. 
30. Arendrup MC.; Cuenca-Estrella M.; Lass-Flo“rl C.; Hope WW. EUCAST technical note on Aspergillus and amphotericin B, itraconazole, and posaconazole. Clin Microbiol Infect. 2012, 18, E248-E250.

31. Theken KN.; Grosser T. Weight-adjusted aspirin for cardiovascular prevention. Lancet. 2018, 392, 361-362.

32. Johnston SC.; Amarenco P.; Denison H.; Evans SR.; Himmelmann A.; James S.; Knutsson M.; Ladenvall P.; Molina CA.; Wang Y.; THALES investigators. Ticagrelor and aspirin or aspirin alone in acute ischemic stroke or TIA. $N$ Engl J Med. 2020, 383, 207-217.

33. Bosetti C.; Santucci C.; Gallus S.; Martinetti M.; La Vecchia C. Aspirin and the risk of colorectal and other digestive tract cancers: an updated meta-analysis through 2019. Ann Oncol. 2020, 31, 558-568.

34. Burn J.; Sheth H.; Elliott F.; Reed L.; Macrae F.; Mecklin JP.; Möslein G.; McRonald FE.; Bertario L.; Evans DG.; et al. Cancer prevention with aspirin in hereditary colorectal cancer (lynch syndrome), 10-year follow-up and registry-based 20-year data in the CAPP2 study: a double-blind, randomised, placebo-controlled trial. Lancet. 2020, 395, 1855-1863.

35. Ng K, Nimeiri HS.; McCleary NJ.; Abrams TA.; Yurgelun MB.; Cleary JM.; Rubinson DA.; Schrag D.; Miksad R.; Bullock AJ.; et al. Effect of high-dose vs standard-dose vitamin $\mathrm{D}_{3}$ supplementation on progression-free survival among patients with advanced or metastatic colorectal cancer: the SUNSHINE randomized clinical trial. JAMA. 2019, 321, 1370-1379.

36. Kouvari M.; Panagiotakos DB.; Chrysohoou C.; Yannakoulia M.; Georgousopoulou EN.; Tousoulis D.; Pitsavos C.; ATTICA study investigators. Dietary vitamin D intake, cardiovascular disease and cardiometabolic risk factors: a sex-based analysis from the ATTICA cohort study. J Hum Nutr Diet. 2020, 33, 708-717.

37. Meltzer DO.; Best TJ.; Zhang H.; Vokes T.; Arora V.; Solway J. Association of vitamin D status and other clinical characteristics with COVID-19 test results. JAMA Netw Open. 2020, 3, e2019722. 38. Arrieta O.; Barrón F.; Padilla MS.; Avilés-Salas A.; Ramírez-Tirado LA.; Arguelles Jiménez MJ.; Vergara E.; Zatarain-Barrón ZL.; Hernández-Pedro N.; Cardona AF.; et al. Effect of metformin plus tyrosine kinase inhibitors compared with tyrosine kinase inhibitors alone in patients with epidermal growth factor receptor-mutated lung adenocarcinoma: a phase 2 randomized clinical trial. JAMA Oncol. 2019, 5, e192553

39. Lee J.; Yesilkanal AE.; Wynne JP.; Frankenberger C.; Liu J.; Yan J.; Elbaz M.; Rabe DC.; Rustandy FD.; Tiwari P.; et al. Effective breast cancer combination therapy targeting BACH1 and mitochondrial metabolism. Nature. 2019, 568, 254-258.

40. Tseng CH. Metformin reduces ovarian cancer risk in Taiwanese women with type 2 diabetes mellitus. Diabetes Metab Res Rev. 2015, 31, 619-26.

41. Cheung KS.; Chan EW.; Wong AYS.; Chen L.; Seto WK.; Wong ICK.; Leung WK. Metformin use and gastric cancer risk in diabetic patients after helicobacter pylori eradication. $J$ Natl Cancer Inst. 2019, 111, 484-489. 
42. M Mohan M.; Al-Talabany S.; McKinnie A.; Mordi IR.; Singh JSS.; Gandy SJ.; Baig F.; Hussain MS.; Bhalraam U.; Khan F.; et al. A randomized controlled trial of metformin on left ventricular hypertrophy in patients with coronary artery disease without diabetes: the METREMODEL trial. Eur Heart J. 2019, 40, 3409-3417.

43. Dy ABC.; Tassone F.; Eldeeb M.; Salcedo-Arellano MJ.; Tartaglia N.; Hagerman R. Metformin as targeted treatment in fragile X syndrome. Clin Genet. 2018, 93, 216-222.

44. Shiers S.; Pradhan G.; Mwirigi J.; Mejia G.; Ahmad A.; Kroener S.; Price T. Neuropathic pain creates an enduring prefrontal cortex dysfunction corrected by the type II diabetic drug metformin but not by gabapentin. $J$ Neurosci. 2018, 38, 7337-7350.

45. Pozzebon Venturini T.; Rossato L.; Chassot F.; Tairine Keller J.; Baldissera Piasentin F.; Morais Santurio J.; Hartz Alves S. In vitro synergistic combinations of pentamidine, polymyxin B, tigecycline and tobramycin with antifungal agents against Fusarium spp. J Med Microbiol. 2016, 65, 770-774.

46. Moneib NA. In-vitro activity of commonly used antifungal agents in the presence of rifampin, polymyxin B and norfloxacin against C. albicans. J Chemother. 1995, 7, 525-9.

47. Zhai B.; Zhou H.; Yang L.; Zhang J.; Jung K.; Giam CZ.; Xiang X.; Lin X. Polymyxin B, in combination with FLC, exerts a potent fungicidal effect. J Antimicrob Chemother. 2010, 65, 931-8. 48. Sardi Jde C.; Pitangui Nde S.; Rodríguez-Arellanes G.; Taylor ML.; Fusco-Almeida AM.; Mendes-Giannini MJ. Highlights in pathogenic fungal biofilms. Rev Iberoam Micol. 2014, 31, 229 .

49. Del Pozo JL.; Francés ML.; Hernáez S.; Serrera A.; Alonso M.; Rubio MF. Effect of AmB alone or in combination with rifampicin or clarithromycin against Candida species biofilms. Int $J$ Artif Organs. 2011, 34, 766-70.

50. Fernández-Rivero ME.; Del Pozo JL.; Valentín A.; de Diego AM.; Pemán J.; Cantón E. Activity of AmB and ANI combined with rifampicin, clarithromycin, ethylenediaminetetraacetic acid, $\mathrm{N}$-acetylcysteine, and farnesol against $C$. tropicalis biofilms. $J$ Fungi (Basel). 2017, 3,16.

51. Lew MA.; Beckett KM.; Levin MJ. Antifungal activity of four tetracycline analogues against C. albicans in vitro: potentiation by AmB. J Infect Dis. 1977, 136, 263-70.

52. El-Azizi M. Enhancement of the in vitro activity of AmB against the biofilms of non-albicans Candida spp. by rifampicin and doxycycline. J Med Microbiol. 2007, 56(Pt 5), 645-649.

53. Miceli MH.; Bernardo SM.; Lee SA. In vitro analyses of the combination of high-dose doxycycline and antifungal agents against $C$. albicans biofilms. Int $J$ Antimicrob Agents. 2009, 34, 326-32.

54. Ku TS.; Palanisamy SK.; Lee SA. Susceptibility of C. albicans biofilms to azithromycin, tigecycline and vancomycin and the interaction between tigecycline and antifungals. Int $J$ Antimicrob Agents. 2010, 36, 441-6.

55. Limon JJ.; Skalski JH.; Underhill DM. Commensal fungi in health and disease. Cell Host Microbe. 2017, 22, 156-165. 
56. Liu J.; Ran Z.; Wang F.; Xin C.; Xiong B.; Song Z. Role of pulmonary microorganisms in the development of chronic obstructive pulmonary disease. Crit Rev Microbiol. 2020, 10, 1-12.

57. Sam QH.; Chang MW.; Chai LY. The fungal mycobiome and its interaction with gut bacteria in the host. Int J Mol Sci. 2017, 18, 330.

58. Thomas S.; Izard J.; Walsh E.; Batich K.; Chongsathidkiet P.; Clarke G.; Sela DA.; Muller AJ.; Mullin JM.; Albert K.; et al. The host microbiome regulates and maintains human health: a primer and perspective for non-microbiologists. Cancer Res. 2017, 77, 1783-1812.

59. Ran Z.; Liu J.; Wang F.; Xin C.; Shen X.; Zeng S.; Song Z.; Xiong B. Analysis of pulmonary microbial diversity in patients with advanced lung cancer based on high-throughput sequencing technology. Zhongguo Fei Ai Za Zhi. 2020, 23, 1031-1038.

60. Lu M.; Yu C.; Cui X.; Shi J.; Yuan L.; Sun S. Gentamicin synergises with azoles against drugresistant C. albicans. Int J Antimicrob Agents. 2018, 51, 107-114.

61. Loreto ES.; Tondolo JS.; Pilotto MB.; Alves SH.; Santurio JM. New insights into the in vitro susceptibility of Pythium insidiosum. Antimicrob Agents Chemother. 2014, 58, 7534-7.

62. Nguyen MH.; Clancy CJ.; Yu YC.; Lewin AS. Potentiation of antifungal activity of AmB by azithromycin against Aspergillus species. Eur J Clin Microbiol Infect Dis. 1997, 16, 846-8.

63. Stergiopoulou T.; Meletiadis J.; Sein T.; Papaioannidou P.; Tsiouris I.; Roilides E.; Walsh TJ. Comparative pharmacodynamic interaction analysis between ciprofloxacin, moxifloxacin and levofloxacin and antifungal agents against $C$. albicans and Aspergillus fumigatus. J Antimicrob Chemother. 2009, 63, 343-8.

64. Ozdek SC.; Miller D.; Flynn PM.; Flynn HW. In vitro antifungal activity of the fourth generation fluoroquinolones against Candida isolates from human ocular infections. Ocul Immunol Inflamm. 2006, 14, 347-51.

65. Deren YT.; Ozdek S.; Kalkanci A.; Akyürek N.; Hasanreisoğlu B. Comparison of antifungal efficacies of moxifloxacin, liposomal AmB, and combination treatment in experimental C. albicans endophthalmitis in rabbits. Can J Microbiol. 2010, 56, 1-7.

66. Sugar AM.; Liu XP.; Chen RJ. Effectiveness of quinolone antibiotics in modulating the effects of antifungal drugs. Antimicrob Agents Chemother. 1997, 41, 2518-21.

67. Gu W.; Yu Q.; Yu C.; Sun S. In vivo activity of FLC/tetracycline combinations in Galleria mellonella with resistant $C$. albicans infection. J Glob Antimicrob Resist. 2018, 13, 74-80.

68. Fiori A.; Van Dijck P. Potent synergistic effect of doxycycline with FLC against $C$. albicans is mediated by interference with iron homeostasis. Antimicrob Agents Chemother. 2012, 56, 3785-96. 69. Gao Y.; Zhang C.; Lu C.; Liu P.; Li Y.; Li H.; Sun S. Synergistic effect of doxycycline and FLC against C. albicans biofilms and the impact of calcium channel blockers. FEMS Yeast Res. 2013, 13, 453-62.

70. Gao Y.; Li H.; Liu S.; Zhang X.; Sun S. Synergistic effect of FLC and doxycycline against $C$. albicans biofilms resulting from calcium fluctuation and downregulation of FLC-inducible efflux pump gene overexpression. J Med Microbiol. 2014, 63, 956-961. 
71. Shi W.; Chen Z.; Chen X.; Cao L.; Liu P.; Sun S. The combination of minocycline and FLC causes synergistic growth inhibition against $C$. albicans: an in vitro interaction of antifungal and antibacterial agents. FEMS Yeast Res. 2010, 10, 885-93.

72. Gao L.; Sun Y.; Yuan M.; Li M.; Zeng T. In vitro and in vivo study on the synergistic effect of minocycline and azoles against pathogenic fungi. Antimicrob Agents Chemother. 2020, 64, e0029020.

73. Rossato L.; Loreto ÉS.; Venturini TP.; Azevedo MI.; Weiblen C.; Botton SA.; Santurio JM.; Alves SH. In vitro interaction of antifungal and antibacterial drugs against $C$. neoformans var. grubii before and after capsular induction. Med Mycol. 2015, 53, 885-9.

74. Lu M.; Yang X.; Yu C.; Gong Y.; Yuan L.; Hao L.; Sun S. Linezolid in combination with azoles induced synergistic effects against $C$. albicans and protected Galleria mellonella against experimental candidiasis. Front Microbiol. 2019, 9, 3142.

75. Vézina C.; Kudelski A.; Sehgal SN. Rapamycin (AY-22,989), a new antifungal antibiotic. I. Taxonomy of the producing streptomycete and isolation of the active principle. J Antibiot (Tokyo). 1975, 28, 721-6.

76. Chowdhary A.; Sharma.; Meis JF. Azole-resistant aspergillosis: epidemiology, molecular mechanisms, and treatment. J Infect Dis. 2017, 216(suppl_3), S436-S444.

77. Cuny GD.; Suebsuwong C.; Ray SS. Inosine-5'-monophosphate dehydrogenase (IMPDH) inhibitors: a patent and scientific literature review (2002-2016). Expert Opin Ther Pat. 2017, 27, 677-690.

78. Kummari LK.; Butler MS.; Furlong E.; Blundell R.; Nouwens A.; Silva AB.; Kappler U.; Fraser JA.; Kobe B.; Cooper MA.; Robertson AAB. Antifungal benzo[b]thiophene 1,1-dioxide IMPDH inhibitors exhibit pan-assay interference (PAINS) profiles. Bioorg Med Chem. 2018, 26, 5408-5419.

79. Banerjee D.; Burkard L.; Panepinto JC. Inhibition of nucleotide biosynthesis potentiates the antifungal activity of AmB. PLoS One. 2014, 9, e87246.

80. Köhler GA.; Gong X.; Bentink S.; Theiss S.; Pagani GM.; Agabian N.; Hedstrom L. The functional basis of mycophenolic acid resistance in C. albicans IMP dehydrogenase. $J$ Biol Chem. 2005, 280, 11295-302.

81. Morrow CA.; Valkov E.; Stamp A.; Chow EW.; Lee IR.; Wronski A.; Williams SJ.; Hill JM.; Djordjevic JT.; Kappler U.; Kobe B.; Fraser JA. De novo GTP biosynthesis is critical for virulence of the fungal pathogen C. neoformans. PLoS Pathog. 2012, 8, e1002957.

82. Zhang M.; Yan H.; Lu M.; Wang D.; Sun S. Antifungal activity of ribavirin used alone or in combination with fluconazole against Candida albicans is mediated by reduced virulence. Int $J$ Antimicrob Agents. 2020, 55, 105804.

83. Yousfi H.; CASsagne C.; Ranque S.; Rolain JM.; Bittar F. Repurposing of ribavirin as an adjunct therapy against invasive Candida strains in an in vitro study. Antimicrob Agents Chemother. 2019, 63, e00263-19. 
84. Sun J.; Hoying JB.; Deymier PA.; Zhang DD.; Wong PK. Cellular architecture regulates collective calcium signaling and cell contractility. PLoS Comput Biol. 2016, 12, e1004955.

85. Bandyopadhyay J.; Lee J.; Bandyopadhyay A. Regulation of calcineurin, a calcium/calmodulin-dependent protein phosphatase, in C. elegans. Mol Cells. 2004, 18, 10-6.

86. Zhang J.; Heitman J.; Chen YL. Comparative analysis of calcineurin signaling between Candida dubliniensis and C. albicans. Commun Integr Biol. 2012, 5, 122-6.

87. Singh N.; Avery RK.; Munoz P.; Pruett TL.; Alexander B.; Jacobs R.; Tollemar JG.; Dominguez EA.; Yu CM.; Paterson DL.; et al. Trends in risk profiles for and mortality associated with invasive aspergillosis among liver transplant recipients. Clin Infect Dis. 2003, 36, 46-52.

88. Torre-Cisneros J.; Mañez R.; Kusne S.; Alessiani M.; Martin M.; Starzl TE. The spectrum of aspergillosis in liver transplant patients: comparison of FK506 and cyclosporine immunosuppression. Transplant Proc. 1991, 23, 3040-1.

89. Li X.; Yu C.; Huang X.; Sun S. Synergistic effects and mechanisms of budesonide in combination with FLC against resistant C. albicans. PLoS One. 2016, 11, e0168936.

90. Sun W.; Wang D.; Yu C.; Huang X.; Li X.; Sun S. Strong synergism of dexamethasone in combination with FLC against resistant $C$. albicans mediated by inhibiting drug efflux and reducing virulence. Int J Antimicrob Agents. 2017, 50, 399-405.

91. Ramondenc I.; Pinel C.; Ambroise-Thomas P.; Grillot R. Does hydrocortisone modify the in vitro susceptibility of Aspergillus fumigatus to ITR and AmB? Med Mycol. 1998, 36, 69-73.

92. Ng TT.; Robson GD.; Denning DW. Hydrocortisone-enhanced growth of Aspergillus spp.: implications for pathogenesis. Microbiology (Reading). 1994, 140 (Pt 9), 2475-9.

93. Jakab Á.; Emri T.; Sipos L.; Kiss Á.; Kovács R.; Dombrádi V.; Kemény-Beke Á.; Balla J.; Majoros L.; Pócsi I. Betamethasone augments the antifungal effect of menadione--towards a novel anti-C. albicans combination therapy. J Basic Microbiol. 2015, 55, 973-81.

94. Myerowitz RL. Gastrointestinal and disseminated candidiasis. An experimental model in the immunosuppressed rat. Arch Pathol Lab Med. 1981, 105, 138-43.

95. Maraki S.; Hajiioannou I.; Anatoliotakis N.; Plataki M.; Chatzinikolaou I.; Zoras O.; Tselentis Y.; Samonis G. Ceftriaxone and dexamethasone affecting yeast gut flora in experimental mice. $J$ Chemother. 1999, 11, 363-6.

96. Jia W.; Zhang H.; Li C.; Li G.; Liu X.; Wei J. The calcineruin inhibitor cyclosporine a synergistically enhances the susceptibility of $C$. albicans biofilms to FLC by multiple mechanisms. BMC Microbiol. 2016, 16, 113.

97. Uppuluri P.; Nett J.; Heitman J.; Andes D. Synergistic effect of calcineurin inhibitors and fluconazole against Candida albicans biofilms. Antimicrob Agents Chemother. 2008, 52, 1127-32. 98. Cordeiro RA.; Macedo RB.; Teixeira CEC.; Marques FJF.; Bandeira TJPG.; Moreira JLB.; Brilhante RSN.; Rocha MFG.; Sidrim JJC. The calcineurin inhibitor cyclosporin A exhibits synergism with antifungals against Candida parapsilosis species complex. J Med Microbiol. 2014, 63(Pt 7), 936-944. 
99. Marchetti O.; Moreillon P.; Glauser MP.; Bille J.; Sanglard D. Potent synergism of the combination of FLC and cyclosporine in C. albicans. Antimicrob Agents Chemother. 2000, 44, 2373-81.

100. Marchetti O.; Entenza JM.; Sanglard D.; Bille J.; Glauser MP.; Moreillon P. FLC plus cyclosporine: a fungicidal combination effective against experimental endocarditis due to $C$. albicans. Antimicrob Agents Chemother. 2000, 44, 2932-8.

101. Kontoyiannis DP.; Lewis RE.; Osherov N.; Albert ND.; May GS. Combination of CAS with inhibitors of the calcineurin pathway attenuates growth in vitro in Aspergillus species. J Antimicrob Chemother. 2003, 51, 313-6.

102. Uppuluri P.; Nett J.; Heitman J.; Andes D. Synergistic effect of calcineurin inhibitors and FLC against C. albicans biofilms. Antimicrob Agents Chemother. 2008, 52, 1127-32.

103. Shinde RB.; Chauhan NM.; Raut JS.; Karuppayil SM. Sensitization of C. albicans biofilms to various antifungal drugs by cyclosporine A. Ann Clin Microbiol Antimicrob. 2012, 11, 27.

104. Schwarz P.; Schwarz PV.; Felske-Zech H.; Dannaoui E. In vitro interactions between ISA and tacrolimus, cyclosporin A or sirolimus against Mucorales. J Antimicrob Chemother. 2019, 74, 19211927.

105. Kubiça TF.; Denardi LB.; Azevedo MI.; Oliveira V.; Severo LC.; Santurio JM.; Alves SH. Antifungal activities of tacrolimus in combination with antifungal agents against FLC-susceptible and FLC-resistant Trichosporon asahii isolates. Braz J Infect Dis. 2016, 20, 539-545.

106. Steinbach WJ.; Schell WA.; Blankenship JR.; Onyewu C.; Heitman J.; Perfect JR. In vitro interactions between antifungals and immunosuppressants against Aspergillus fumigatus. Antimicrob Agents Chemother. 2004, 48,1664-9.

107. High KP.; Washburn RG. Invasive aspergillosis in mice immunosuppressed with cyclosporin A, tacrolimus (FK506), or sirolimus (rapamycin). J Infect Dis. 1997, 175, 222-5.

108. Schwarz P.; Dannaoui E. In vitro interaction between ISA and tacrolimus, cyclosporin A, or sirolimus against Aspergillus species. J Fungi (Basel). 2020, 6, 103.

109. Shalit I.; Shadkchan Y.; Mircus G.; Osherov N. In vitro synergy of CAS with licensed and novel antifungal drugs against clinical isolates of Fusarium spp. Med Mycol. 2009;47, 457-62.

110. Sun S.; Li Y.; Guo Q.; Shi C.; Yu J.; Ma L. In vitro interactions between tacrolimus and azoles against $C$. albicans determined by different methods. Antimicrob Agents Chemother. 2008, 52, 40917.

111. Sugita T.; Tajima M.; Tsubuku H.; Tsuboi R.; Nishikawa A. A new calcineurin inhibitor, pimecrolimus, inhibits the growth of Malassezia spp. Antimicrob Agents Chemother. 2006, 50, 2897-8.

112. Cruz MC.; Goldstein AL.; Blankenship J.; Del Poeta M.; Perfect JR.; McCusker JH.; Bennani YL.; Cardenas ME.; Heitman J. Rapamycin and less immunosuppressive analogs are toxic to Candida albicans and Cryptococcus neoformans via FKBP12-dependent inhibition of TOR. Antimicrob Agents Chemother. 2001, 45, 3162-70. 
113. Bastidas RJ.; Shertz CA.; Lee SC.; Heitman J.; Cardenas ME. Rapamycin exerts antifungal activity in vitro and in vivo against Mucor circinelloides via FKBP12-dependent inhibition of Tor. Eukaryot Cell. 2012, 11, 270-81.

114. Esfahani AN.; Golestannejad Z.; Khozeimeh F.; Dehghan P.; Maheronnaghsh M.; Zarei Z. Antifungal effect of atorvastatin against Candida species in comparison to fluconazole and nystatin. Med Pharm Rep. 2019, 92, 368-373.

115. Callegari S.; McKinnon RA.; Andrews S.; de Barros Lopes MA. Atorvastatin-induced cell toxicity in yeast is linked to disruption of protein isoprenylation. FEMS Yeast Res. 2010, 10, 18898.

116. Tashiro M.; Kimura S.; Tateda K.; Saga T.; Ohno A.; Ishii Y.; Izumikawa K.; Tashiro T.; Kohno S.; Yamaguchi K. Pravastatin inhibits farnesol production in Candida albicans and improves survival in a mouse model of systemic candidiasis. Med Mycol. 2012, 50, 353-60.

117. Nash JD.; Burgess DS.; Talbert RL. Effect of fluvastatin and pravastatin, HMG-CoA reductase inhibitors, on fluconazole activity against Candida albicans. J Med Microbiol. 2002, 51,105-109.

118. Brilhante RS.; Caetano EP.; Oliveira JS.; Castelo-Branco Dde S.; Souza ER.; Alencar LP.; Cordeiro Rde A.; Bandeira Tde J.; Sidrim JJ.; Rocha MF. Simvastatin inhibits planktonic cells and biofilms of Candida and Cryptococcus species. Braz J Infect Dis. 2015, 19, 459-65.

119. Nyilasi I.; Kocsubé S.; Krizsán K.; Galgóczy L.; Pesti M.; Papp T.; Vágvölgyi C. In vitro synergistic interactions of the effects of various statins and azoles against some clinically important fungi. FEMS Microbiol Lett. 2010, 307, 175-84.

120. Zhou Y.; Yang H.; Zhou X.; Luo H.; Tang F.; Yang J.; Alterovitz G.; Cheng L.; Ren B. Lovastatin synergizes with itraconazole against planktonic cells and biofilms of Candida albicans through the regulation on ergosterol biosynthesis pathway. Appl Microbiol Biotechnol. 2018, 102, 5255-5264.

121. Chamilos G.; Lewis RE.; Kontoyiannis DP. Lovastatin has significant activity against zygomycetes and interacts synergistically with VRC. Antimicrob Agents Chemother. 2006, 50, 96 103.

122. Westermeyer C.; Macreadie IG. Simvastatin reduces ergosterol levels, inhibits growth and causes loss of mtDNA in C. glabrata. FEMS Yeast Res. 2007, 7, 436-41.

123. Cabral ME.; Figueroa LI.; Fariña JI. Synergistic antifungal activity of statin-azole associations as witnessed by Saccharomyces cerevisiae- and Candida utilis-bioassays and ergosterol quantification. Rev Iberoam Micol. 2013, 30, 31-8.

124. Silva THS.; Araújo CV.; Santos KMDC.; Alves NDS.; Gomes THS.; Silva AKFE.; Silva NCLDS.; Damasceno Júnior ECB.; Carvalho AMA.; Mendes MGA.; et al. Synergic effect of simvastatin in combination with amphotericin B against environmental strains of Cryptococcus neoformans from northeastern Brazil: a prospective experimental study. Sao Paulo Med J. 2020, $138,40-46$. 
125. Ajdidi A.; Sheehan G.; Abu Elteen K.; Kavanagh K. Assessment of the in vitro and in vivo activity of atorvastatin against Candida albicans. J Med Microbiol. 2019, 68, 1497-1506.

126. Lima WG.; Alves-Nascimento LA.; Andrade JT.; Vieira L.; de Azambuja Ribeiro RIM.; Thomé RG.; Dos Santos HB.; Ferreira JMS.; Soares AC. Are the statins promising antifungal agents against invasive candidiasis? Biomed Pharmacother. 2019, 111, 270-281.

127. Ribeiro NQ.; Costa MC.; Magalhães TFF.; Carneiro HCS.; Oliveira LV.; Fontes ACL.; Santos JRA.; Ferreira GF.; Araujo GRS.; Alves V.; Frases S.; Paixão TA.; de Resende Stoianoff MA.; Santos DA. Atorvastatin as a promising anticryptococcal agent. Int J Antimicrob Agents. 2017, 49 , 695-702.

128. Chin NX.; Weitzman I.; Della-Latta P. In vitro activity of fluvastatin, a cholesterol-lowering agent, and synergy with fluconazole and ITR against Candida species and C. neoformans. Antimicrob Agents Chemother. 1997, 41, 850-2.

129. Eldesouky HE.; Salama EA.; Li X.; Hazbun TR.; Mayhoub AS.; Seleem MN. Repurposing approach identifies pitavastatin as a potent azole chemosensitizing agent effective against azoleresistant Candida species. Sci Rep. 2020, 10, 7525.

130. Ajdidi A.; Sheehan G.; Kavanagh K. Exposure of Aspergillus fumigatus to atorvastatin leads to altered membrane permeability and induction of an oxidative stress response. $J$ Fungi (Basel). 2020, 6,42 .

131. Yu Q.; Ding X.; Zhang B.; Xu N.; Jia C.; Mao J.; Zhang B.; Xing L.; Li M. Inhibitory effect of verapamil on C. albicans hyphal development, adhesion and gastrointestinal colonization. FEMS Yeast Res. 2014, 14, 633-41.

132. Yu Q.; Xiao C.; Zhang K.; Jia C.; Ding X.; Zhang B.; Wang Y.; Li M. The calcium channel blocker verapamil inhibits oxidative stress response in C. albicans. Mycopathologia. 2014, 177, 167-77.

133. Yu Q.; Ding X.; Xu N.; Cheng X.; Qian K.; Zhang B.; Xing L.; Li M. In vitro activity of verapamil alone and in combination with FLC or tunicamycin against $C$. albicans biofilms. Int $J$ Antimicrob Agents. 2013, 41, 179-82.

134. Zeng Q.; Zhang Z.; Chen P.; Long N.; Lu L.; Sang H. In vitro and in vivo efficacy of a synergistic combination of ITR and verapamil against Aspergillus fumigatus. Front Microbiol. 2019, 10,1266 .

135. Alnajjar LM.; Bulatova NR.; Darwish RM. Evaluation of four calcium channel blockers as FLC resistance inhibitors in C. glabrata. J Glob Antimicrob Resist. 2018, 14, 185-189.

136. Homa M.; Hegedűs K.; Fülöp Á.; Wolfárt V.; Kadaikunnan S.; Khaled JM.; Alharbi NS.; Vágvölgyi C.; Galgóczy L. In vitro activity of calcium channel blockers in combination with conventional antifungal agents against clinically important filamentous fungi. Acta Biol Hung. 2017, $68,334-344$.

137. Bulatova NR.; Darwish RM. Effect of chemosensitizers on minimum inhibitory concentrations of FLC in C. albicans. Med Princ Pract. 2008,17, 117-21.

138. Nattel S.; Singh BN. Evolution, mechanisms, and classification of antiarrhythmic drugs: focus on class III actions. Am J Cardiol. 1999, 84(9A), 11R-19R. 
139. Kodama I.; Kamiya K.; Toyama J. Amiodarone: ionic and cellular mechanisms of action of the most promising class III agent. Am J Cardiol. 1999, 84(9A), 20R-28R.

140. Dorian P. Mechanisms of action of class III agents and their clinical relevance. Europace. 2000, 1 Suppl C, C6-9.

141. Courchesne WE. Characterization of a novel, broad-based fungicidal activity for the antiarrhythmic drug amiodarone. J Pharmacol Exp Ther. 2002, 300, 195-9.

142. Knorre DA.; Krivonosova TN.; Markova OV.; Severin FF. Amiodarone inhibits multiple drug resistance in yeast Saccharomyces cerevisiae. Arch Microbiol. 2009, 191, 675-9.

143. Courchesne WE.; Tunc M.; Liao S. Amiodarone induces stress responses and calcium flux mediated by the cell wall in Saccharomyces cerevisiae. Can J Microbiol. 2009, 55, 288-303.

144. Bagar T.; Benčina M. Antiarrhythmic drug amiodarone displays antifungal activity, induces irregular calcium response and intracellular acidification of Aspergillus niger - amiodarone targets calcium and $\mathrm{pH}$ homeostasis of A. niger. Fungal Genet Biol. 2012, 49, 779-91.

145. Afeltra J.; Vitale RG.; Mouton JW.; Verweij PE. Potent synergistic in vitro interaction between nonantimicrobial membrane-active compounds and ITR against clinical isolates of Aspergillus fumigatus resistant to ITR. Antimicrob Agents Chemother. 2004, 48, 1335-43.

146. Gamarra S.; Rocha EM.; Zhang YQ.; Park S.; Rao R.; Perlin DS. Mechanism of the synergistic effect of amiodarone and FLC in C. albicans. Antimicrob Agents Chemother. 2010, 54, 1753-61.

147. da Silva CR.; de Andrade Neto JB.; Sidrim JJ.; Angelo MR.; Magalhães HI.; Cavalcanti BC.; Brilhante RS.; Macedo DS.; de Moraes MO.; Lobo MD.; Grangeiro TB.; Nobre Júnior HV. Synergistic effects of amiodarone and FLC on C. tropicalis resistant to FLC. Antimicrob Agents Chemother. 2013, 57, 1691-700.

148. Gupta SS.; Ton VK.; Beaudry V.; Rulli S.; Cunningham K.; Rao R. Antifungal activity of amiodarone is mediated by disruption of calcium homeostasis. J Biol Chem. 2003, 278, 28831-9.

149. Afeltra J.; Verweij PE. Antifungal activity of non-antifungal drugs. Eur J Clin Microbiol Infect Dis. 2003, 22, 397-407.

150. Wood NC.; Nugent KM. Inhibitory effects of chlorpromazine on Candida species. Antimicrob Agents Chemother. 1985, 27, 692-4.

151. Rossato L.; Loreto ÉS.; Zanette RA.; Chassot F.; Santurio JM.; Alves SH. In vitro synergistic effects of chlorpromazine and sertraline in combination with AmB against $C$. neoformans var. grubii. Folia Microbiol (Praha). 2016, 61, 399-403.

152. Sharma S.; Kaur H.; Khuller GK. Cell cycle effects of the phenothiazines: trifluoperazine and chlorpromazine in C. albicans. FEMS Microbiol Lett. 2001, 199, 185-90.

153. Galgóczy L.; Bácsi A.; Homa M.; Virágh M.; Papp T.; Vágvölgyi C. In vitro antifungal activity of phenothiazines and their combination with $\mathrm{AmB}$ against different Candida species. Mycoses. 2011, 54, e737-43.

154. Ben-Gigi G.; Polacheck I.; Eilam Y. In vitro synergistic activity of KET with trifluoperazine and with chlorpromazine against medically important yeasts. Chemotherapy. 1988, 34, 96-100.

155. Wang Y.; Casadevall A. Susceptibility of melanized and nonmelanized C. neoformans to the melanin-binding compounds trifluoperazine and chloroquine. Antimicrob Agents Chemother. 1996, 40, 541-5. 
156. Galgóczy L.; Papp T.; Kovács L.; Ordögh L.; Vágvölgyi C. In vitro activity of phenothiazines and their combinations with $\mathrm{AmB}$ against Zygomycetes causing rhinocerebral zygomycosis. Med Mycol. 2009, 47, 331-5.

157. Vitale RG.; Afeltra J.; Meis JF.; Verweij PE. Activity and post antifungal effect of chlorpromazine and trifluopherazine against Aspergillus, Scedosporium and zygomycetes. Mycoses. 2007, 50, 270-6.

158. Homa M.; Galgóczy L.; Tóth E.; Tóth L.; Papp T.; Chandrasekaran M.; Kadaikunnan S.; Alharbi NS.; Vágvölgyi C. In vitro antifungal activity of antipsychotic drugs and their combinations with conventional antifungals against Scedosporium and Pseudallescheria isolates. Med Mycol. 2015, 53, 890-5.

159. Krajewska-Kułak E.; Niczyporuk WW. Anticandidal activity of flunarizine. Mater Med Pol. 1993, 25,143-4.

160. Latendresse G.; Elmore C.; Deneris A. Selective serotonin reuptake inhibitors as first-line antidepressant therapy for perinatal depression. J Midwifery Womens Health. 2017, 62, 317-328.

161. Bandelow B.; Michaelis S.; Wedekind D. Treatment of anxiety disorders. Dialogues Clin Neurosci. 2017, 19, 93-107.

162. Oliveira AS.; Gaspar CA.; Palmeira-de-Oliveira R.; Martinez-de-Oliveira J.; Palmeira-deOliveira A. Anti-Candida activity of fluoxetine alone and combined with FLC: a synergistic action against FLC-resistant strains. Antimicrob Agents Chemother. 2014, 58, 4224-6.

163. Gu W.; Guo D.; Zhang L.; Xu D.; Sun S. The synergistic effect of azoles and fluoxetine against resistant $C$. albicans strains is attributed to attenuating fungal virulence. Antimicrob Agents Chemother. 2016, 60, 6179-88.

164. Naglik JR.; Challacombe SJ.; Hube B. Candida albicans secreted aspartyl proteinases in virulence and pathogenesis. Microbiol Mol Biol Rev. 2003, 67, 400-28.

165. Jiang L.; Zheng L.; Sun KA.; Zhou P.; Xu R.; Gu J.; Wei X. In vitro and in vivo evaluation of the antifungal activity of fluoxetine combined with antifungals against $C$. albicans biofilms and oral candidiasis. Biofouling. 2020, 36, 537-548.

166. Treviño-Rangel Rde J.; Villanueva-Lozano H.; Hernández-Rodríguez P.; Martínez-Reséndez MF.; García-Juárez J.; Rodríguez-Rocha H.; González GM. Activity of sertraline against $C$. neoformans: in vitro and in vivo assays. Med Mycol. 2016, 54, 280-6.

167. Treviño-Rangel RJ.; Villanueva-Lozano H.; Méndez-Galomo KS.; Solís-Villegas EM.; Becerril-García MA.; Montoya AM.; Robledo-Leal ER.; González GM. In vivo evaluation of the antifungal activity of sertraline against Aspergillus fumigatus. $J$ Antimicrob Chemother. 2019, 74, 663-666.

168. Oliveira AS.; Martinez-de-Oliveira J.; Donders GGG.; Palmeira-de-Oliveira R.; Palmeirade-Oliveira A. Anti-Candida activity of antidepressants sertraline and fluoxetine: effect upon preformed biofilms. Med Microbiol Immunol. 2018, 207, 195-200.

169. Paul S.; Mortimer RB.; Mitchell M. Sertraline demonstrates fungicidal activity in vitro for Coccidioides immitis. Mycology. 2016, 7, 99-101.

170. Cong L.; Liao Y.; Yang S.; Yang R. In vitro antifungal activity of sertraline and synergistic effects in combination with antifungal drugs against planktonic forms and biofilms of clinical Trichosporon asahii isolates. PLoS One. 2016, 11, e0167903. 
171. Gowri M.; Jayashree B.; Jeyakanthan J.; Girija EK. Sertraline as a promising antifungal agent: inhibition of growth and biofilm of Candida auris with special focus on the mechanism of action in vitro. J Appl Microbiol. 2020, 128, 426-437.

172. Fitzpatrick FA. Cyclooxygenase enzymes: regulation and function. Curr Pharm Des. 2004, $10,577-88$.

173. Alem MA.; Douglas LJ. Effects of aspirin and other nonsteroidal anti-inflammatory drugs on biofilms and planktonic cells of C. albicans. Antimicrob Agents Chemother. 2004, 48, 41-7.

174. Abdelmegeed E.; Shaaban MI. Cyclooxygenase inhibitors reduce biofilm formation and yeast-hypha conversion of FLC resistant C. albicans. J Microbiol. 2013, 51, 598-604.

175. Ogundeji AO.; Pohl CH.; Sebolai OM. Repurposing of aspirin and ibuprofen as candidate anti-Cryptococcus drugs. Antimicrob Agents Chemother. 2016, 60, 4799-808.

176. Yang S.; Liao Y.; Cong L.; Lu X.; Yang R. In vitro interactions between non-steroidal antiinflammatory drugs and antifungal agents against planktonic and biofilm forms of Trichosporon asahii. PLoS One. 2016, 11, e0157047.

177. Borba-Santos LP.; Nucci M.; Ferreira-Pereira A.; Rozental S. Anti-Sporothrix activity of ibuprofen combined with antifungal. Braz J Microbiol. 2020.

178. Alves LR.; Oliveira C.; Goldenberg S. Eukaryotic translation elongation factor-1 alpha is associated with a specific subset of mRNAs in Trypanosoma cruzi. BMC Microbiol. 2015, 15, 104. 179. Nargesi S.; Rezaie S. Investigation an antifungal activity of diclofenac sodium against hyphae formation in Aspergillus Fumigatus with attention to the expression of Ef-1 Gene. Iran J Public Health. 2018, 47, 770-772.

180. Wu Y.; Totten M.; Memon W.; Ying C.; Zhang SX. In vitro antifungal susceptibility of the emerging multidrug-resistant pathogen Candida auris to miltefosine alone and in combination with amphotericin B. Antimicrob Agents Chemother. 2020, 64, e02063-19.

181. Hai TP.; Van AD.; Ngan NTT.; Nhat LTH.; Lan NPH.; Vinh Chau NV.; Thwaites GE.; Krysan D.; Day JN. The combination of tamoxifen with amphotericin B, but not with fluconazole, has synergistic activity against the majority of clinical isolates of Cryptococcus neoformans. Mycoses. 2019, 62, 818-825.

182. Yang J.; Gao L.; Yu P.; Kosgey JC.; Jia L.; Fang Y.; Xiong J.; Zhang F. In vitro synergy of azole antifungals and methotrexate against Candida albicans. Life Sci. 2019, 235, 116827.

183. Kathwate GH.; Shinde RB.; Karuppayil SM. Antiepileptic drugs inhibit growth, dimorphism, and biofilm mode of growth in human pathogen Candida albicans. Assay Drug Dev Technol. 2015, $13,307-12$. 
Table 1 Summary of antibacterial drugs with antifungal activity

\begin{tabular}{|c|c|c|c|c|c|c|}
\hline Antibiotics & Fungus & In vitro (MIC: $\mu \mathrm{g} / \mathrm{mL}$ ) & In vivo & $\begin{array}{l}\text { In combination } \\
\text { (synergistic effects) }\end{array}$ & Relevant molecular mechanism & Ref. \\
\hline Tobramycin & Fusarium spp. & $>64$ & - & VRC, AmB & Probably increases permeability of the cell wall and cell membrane. & [45] \\
\hline \multirow[t]{2}{*}{ Gentamicin } & Resistant-azole C. albicans & $>512$ & G. mellonella & FLC & ( 1 ) Suppresses overexpression of the efflux pump. & [60] \\
\hline & & & & & (II) Reduces phospholipase activity of resistant C. albicans. & \\
\hline \multirow[t]{3}{*}{ Clarithromycin } & C. tropicalis & - & - & AmB, ANI & - & [50] \\
\hline & C. parapsilosis, C. glabrata, C. albicans & No effects & & AmB & & [49] \\
\hline & Pythium insidiosum & $0.25-8$ & & - & & [61] \\
\hline \multirow[t]{2}{*}{ Azithromycin } & Pythium insidiosum & $1-16$ & - & - & - & [61] \\
\hline & Aspergillus spp. & No effects & & AmB & Probably inhibits mitochondrial protein synthesis. & [62] \\
\hline Norfloxacin & C. albicans & - & - & MIA & - & [46] \\
\hline Levofloxacin & C. albicans, A. fumigatus & + & - & AmB, CAS & Probably inhibits fungal DNA replication by binding to fungal topoisomerase. & [63] \\
\hline Gatifloxacin & Candida spp. & + & - & - & - & [64] \\
\hline \multirow[t]{2}{*}{ Moxifloxacin } & C. albicans & $+[64]$ & - & Liposomal AmB [65], & Probably inhibits fungal DNA replication by binding to fungal topoisomerase.[63] & {$[63-65]$} \\
\hline & & & & CAS [63] & & \\
\hline \multirow[t]{2}{*}{ Ciprofloxacin } & C. albicans & + & - & AmB & Probably inhibits fungal DNA replication by binding to C. albicans topoisomerase. & [63] \\
\hline & A. fumigatus & + & & AmB, CAS, ARC & & \\
\hline \multirow[t]{2}{*}{ Trovafloxacin } & C. albicans & No effects & Murine & FLC, AmB & - & [66] \\
\hline & C. tropicalis, C. neoformans & No effects & - & FLC, AmB & & \\
\hline Tetracycline & C. albicans & $320-2560[51]$ & G. mellonella & AmB, FLC & - & {$[51,67]$} \\
\hline Demeclocycline & C. albicans & 640 & - & AmB & - & [51] \\
\hline \multirow[t]{3}{*}{ Doxycycline } & C. parapsilosis, C. krusei, C. glabrata & No effects & - & AmB & Probably inhibits protein synthesis. & [52] \\
\hline & C. albicans & $640-1280[51]$ & G. mellonella & AmB, FLC, CAS & ( I ) Inhibits FLC-inducible efflux pump gene overexpression [70]. & {$[51,53,67-70]$} \\
\hline & & & & & (II) Disturbs calcium homeostasis [69,70]. & \\
\hline
\end{tabular}


(III) Disturbs iron homeostasis [68]

\begin{tabular}{|c|c|c|c|c|c|c|}
\hline \multirow[t]{3}{*}{ Minocycline } & \multirow{3}{*}{$\begin{array}{l}\text { C. albicans (fluconazole-resistance) } \\
\text { A. fumigatus } \\
\text { A. flavus, F. solani, F. oxysporum }\end{array}$} & \multirow{3}{*}{$\begin{array}{l}256-512 \\
0.125-4[61] \\
0.125-4[61]\end{array}$} & \multirow{3}{*}{$\begin{array}{l}\text { - } \\
\text { G. mellonella } \\
\text { - }\end{array}$} & \multirow{3}{*}{$\begin{array}{l}\text { AmB, FLC } \\
\text { ITR, VRC, POS } \\
\text { ITR, VRC, POS }\end{array}$} & \multirow{3}{*}{$\begin{array}{l}\text { Disturbs calcium homeostasis [71]. } \\
\text { Probably interferes with the balance of cellular electrolytes and loss of } \\
\text { mitochondrial function. }\end{array}$} & \multirow{3}{*}{$\begin{array}{l}{[51,71]} \\
{[72]}\end{array}$} \\
\hline & & & & & & \\
\hline & & & & & & \\
\hline \multirow[t]{2}{*}{ Tigecycline } & C. albicans & 2048 & - & AmB, FLC, CAS & - & [54] \\
\hline & Fusarium spp. & $0.25-4$ & & VRC, AmB & Inhibits the synthesis of protein [45]. & [61] \\
\hline \multirow[t]{5}{*}{ Polymyxin B } & C. albicans & - & - & AmB, KET, MIA & Probably alters cell membrane permeability. & [46] \\
\hline & Fusarium spp. & 4-16 & & VRC, AmB & Probably disturbs the synthesis of ergosterol. & [45] \\
\hline & C. neoformans & $8-256$ & & FLC & Probably through binding anionic lipids on fungal membrane and destroys & [47] \\
\hline & Rhizopus oryzae & 32 & & - & membrane integrity. & \\
\hline & A. fumigatus & $28-56$ & & - & & \\
\hline \multirow[t]{2}{*}{ Rifampicin } & C. tropicalis & - & - & AmB, ANI & - & {$[50]$} \\
\hline & C. parapsilosis, C. glabrata, C. albicans, C. krusei & No effects & & AmB & Probably disturbs RNA synthesis in the presence of AmB. & {$[52,61]$} \\
\hline \multirow[t]{3}{*}{ Linezolid } & Pythium insidiosum & $1-32$ & - & - & Inhibits protein synthesis. & [61] \\
\hline & C. neoformans & $>64$ & - & AmB & - & [73] \\
\hline & C. albican & $>512$ & G. mellonella & FLC, ITR, VRC & $\begin{array}{l}\text { Probably inhibits mitochondrial protein synthesis and interferes with the } \\
\text { induction of stress-response mitochondrial chaperones. }\end{array}$ & [74] \\
\hline
\end{tabular}

Note: VRC, voriconazole; AmB, amphotericin B; FLC, fluconazole; ITR, itraconazole; CTZ, clotrimazole; POS, posaconazole; ANI, anidulafungin; MIA, micafungin; CAS, caspofungin; KET, ketoconazole; -, no studies were mentioned in the corresponding references; +, the drug has antifungal effect, but no specific data in the corresponding references. 
( II) Reduces the activity of extracellular phospholipases and the formation

of biofilm.

(III) Promotes apoptosis by the accumulation of ROS. 
Table 3 Summary of statin drugs with antifungal activity

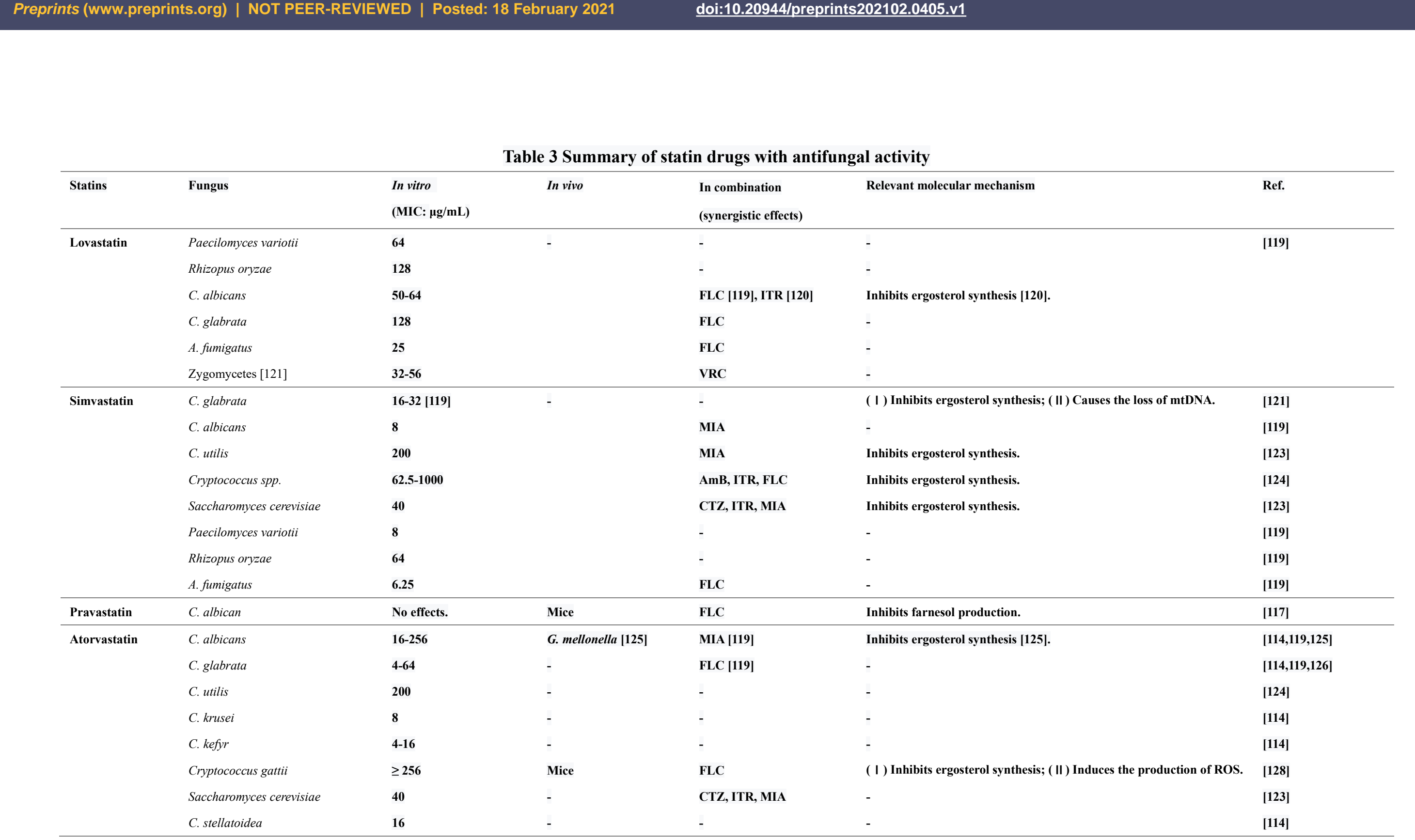




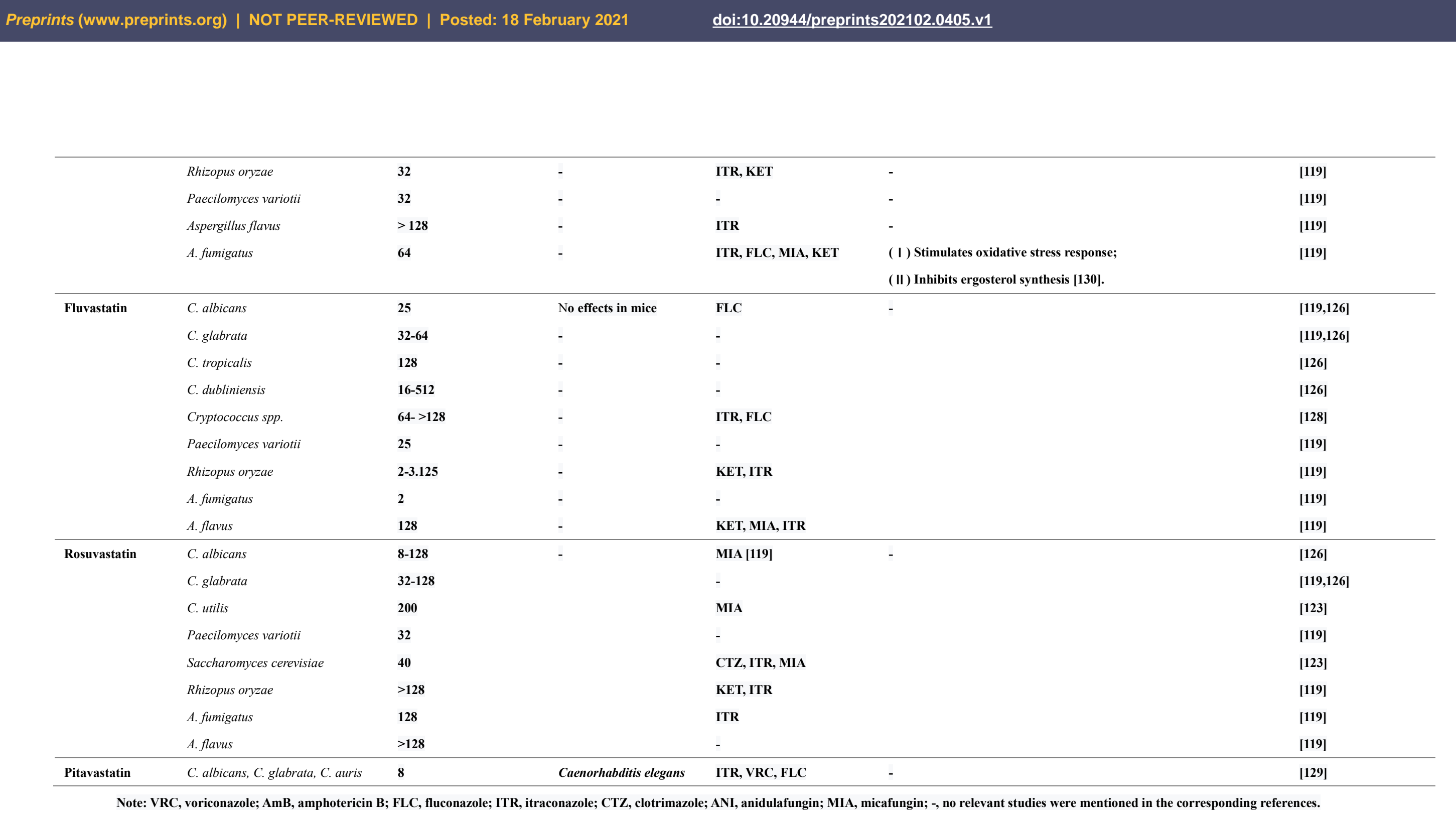

Note: VRC, voriconazole; AmB, amphotericin B; FLC, fluconazole; ITR, itraconazole; CTZ, clotrimazole; ANI, anidulafungin; MIA, micafungin; -, no relevant studies were mentioned in the corresponding references.

Ne: VRC, vaing

Preprints (WwW.preprints.org) | NOT PEER-REVIEWED | POsted: 18 February 2021 \\ doi:10.20944/preprints202102.0405.v1}

(a)

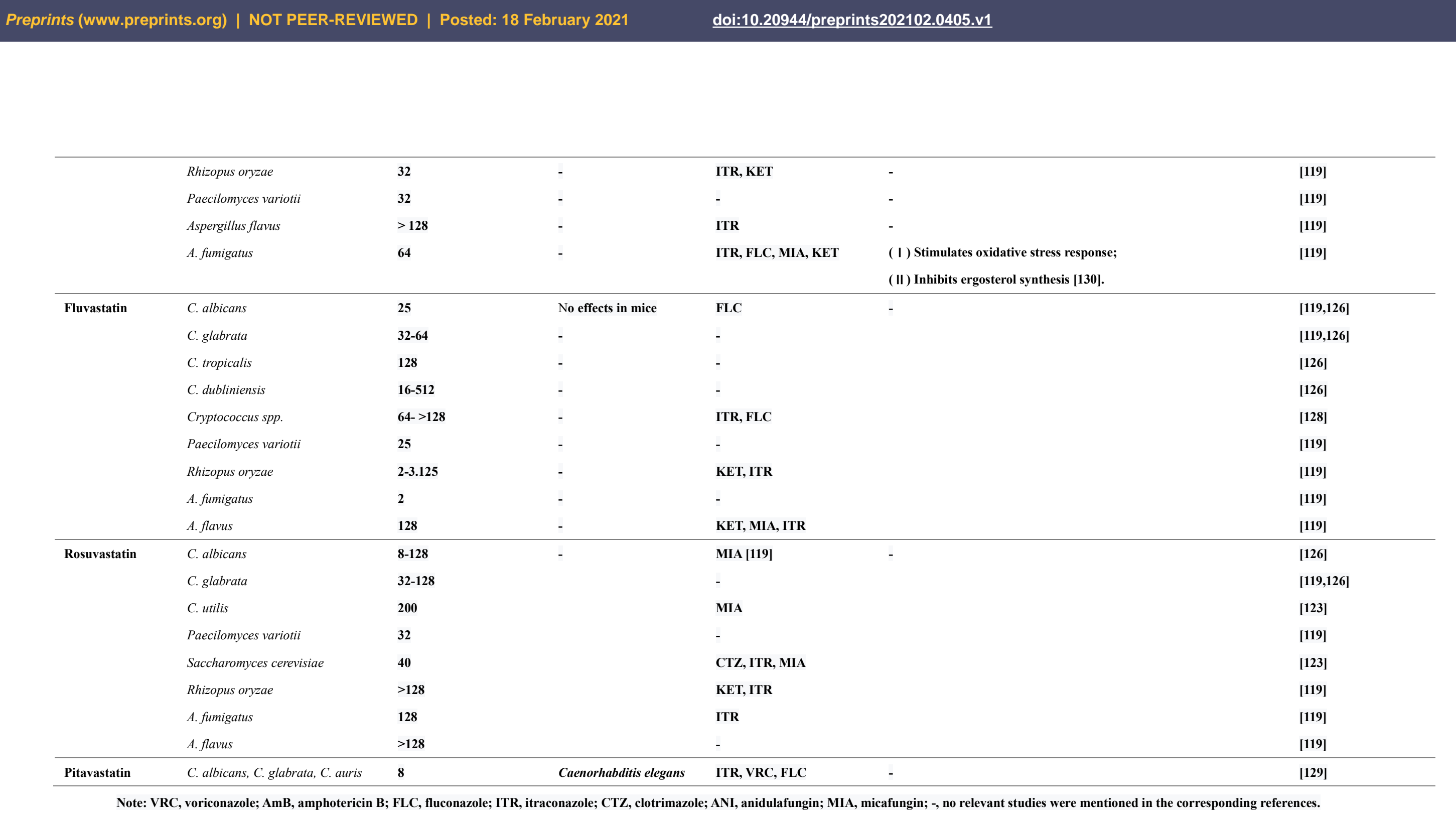


Fig. 1. The antifungal targets of the above-mentioned non-antifungal agents. "?", the target is not clear; COX, cyclooxygenase; PGs, prostaglandins; NSAIDs, Nonsteroidal anti-inflammatory drugs.

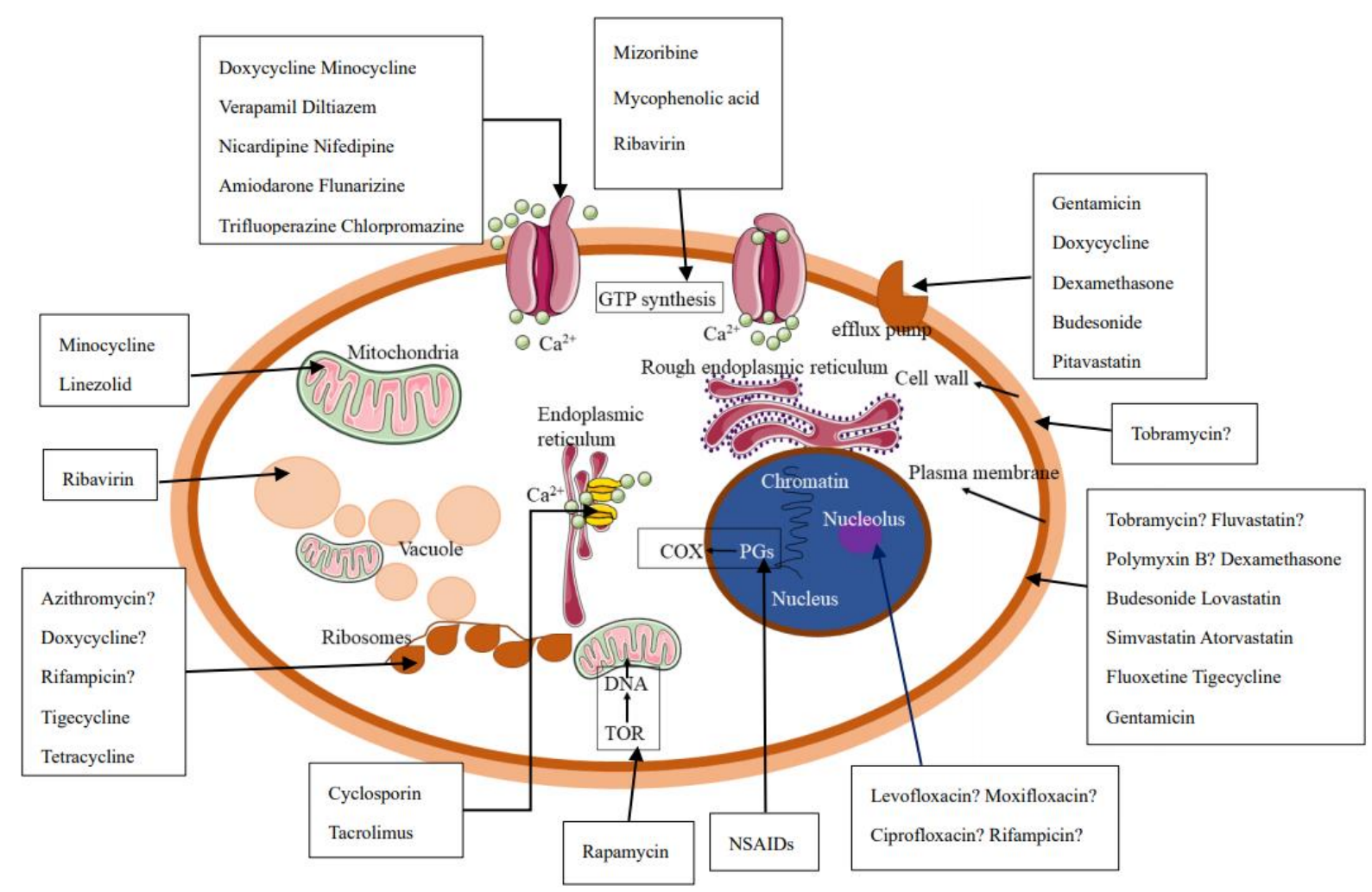

